\title{
Adaptation of SARS-CoV-2 in BALB/c mice for testing vaccine efficacy
}

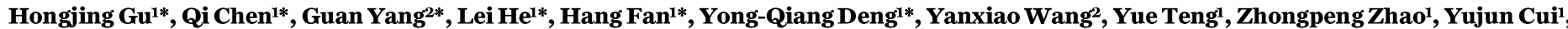
Yuchang Li', Xiao-Feng Li', Jiangfan Li', Na-Na Zhang', Xiaolan Yang1, Shaolong Chen', Yan Guo ${ }^{1}$, Guangyu Zhao', Xiliang Wang1, De-Yan Luo $^{1}$, Hui Wang1, Xiao Yang ${ }^{2}$, Yan Li ${ }^{3}$, Gencheng Han ${ }^{3}$, Yuxian He ${ }^{4}$, Xiaojun Zhou ${ }^{5}$, Shusheng Geng ${ }^{6}$, Xiaoli Sheng ${ }^{6}$, Shibo Jiang ${ }^{7}+$, , Shihui Sun1+*, Cheng-Feng Qin1+\$, Yusen Zhou 1 \$

1 State Key Laboratory of Pathogen and Biosecurity, Beijing Institute of Microbiology and Epidemiology, Academy of Military Medical Sciences, Beijing 100071, China. 2State Key Laboratory of Proteomics, Beijing Proteome Research Center, National Center for Protein Sciences (Beijing), Beijing Institute of Lifeomics, Beijing 102206, China. 3Institute of Military Cognition and Brain Sciences, Beijing 100850, China. 4Institute of Pathogen Biology, Chinese Academy of Medical Sciences and Peking Union Medical College, Beijing100730, China. ${ }^{5}$ Laboratory Animal Center, Academy of Military Medical Sciences, Beijing 100071, China. ${ }^{6}$ Beijing JOINN Biologics Co. Ltd, Beijing 100176, China. ${ }^{7}$ Key Laboratory of Medical Molecular Virology (MOE/NHC/CAMS), School of Basic Medical Sciences, Fudan University, Shanghai 200032, China.
\end{abstract}

*These authors contributed equally to this work.

†Corresponding author. Email: shibojiang@fudan.edu.cn (S.J.); sunsh01@163.com (S.S.); qincf@bmi.ac.cn (C.-F.Q.)

†These authors contributed equally to this work.

§Deceased.

The ongoing COVID-19 pandemic has prioritized the development of small animal models for SARS-CoV-2. Herein, we adapted a clinical isolate of SARS-CoV-2 by serial passaging in the respiratory tract of aged BALB/c mice. The resulting mouse-adapted strain at passage 6 (termed MASCp6) showed increased infectivity in mouse lung, and led to interstitial pneumonia and inflammatory responses in both young and aged mice following intranasal inoculation. Deep sequencing revealed a panel of adaptive mutations potentially associated with the increased virulence. In particular, the N501Y mutation is located at the receptor binding domain (RBD) of the spike protein. The protective efficacy of a recombinant RBD vaccine candidate was validated using this model. Thus, this mouse-adapted strain and associated challenge model should be of value in evaluating vaccines and antivirals against SARS-CoV-2.

The pandemic of coronavirus disease 2019 (COVID-19) caused by the newly emerged severe acute respiratory syndrome coronavirus 2 (SARS-CoV-2) has become a global health crisis (1-3). In the absence of protective immunity in the whole human population (4), SARS-CoV-2 has exhibited an unprecedented human-to-human transmission capability. Although several vaccine candidates are being currently tested in clinical trials, no commercial COVID-19 vaccine is presently available.

SARS-CoV-2 belongs to the Betacoronavirus genus of the Coronaviridae family, along with two other closely related highly pathogenic viruses, SARS-CoV and Middle East respiratory syndrome coronavirus (MERS-CoV). SARS-CoV-2 has a positive-sense, single-stranded RNA genome of $30 \mathrm{~kb}$ in length, which is coated by the inner nucleocapsid $(\mathrm{N})$ proteins and outer envelope made up of membrane (M) and envelope (E) proteins, as well as spike (S) proteins. Like SARS$\mathrm{CoV}$, the S protein of SARS-CoV-2 mediates viral entry into host cells by binding to their shared receptor, angiotensinconverting enzyme 2 (ACE2), via the receptor-binding domain (RBD) (1). Previously, we and others have demonstrated that the RBD of SARS-CoV and MERS-CoV contain major conformation-dependent neutralizing epitopes and are capable of eliciting potent neutralizing antibodies in immunized animals, thus representing promising targets for vaccine development (5-8).

Small animal models that recapitulate SARS-CoV-2 infection are urgently needed. As SARS-CoV-2 does not use mouse ACE2 as its receptor (1), wild-type mice are thought to be less susceptible to SARS-CoV-2. Transgenic mice expressing human ACE2 have been developed via different strategies. Such mice have been used previously to study SARS-CoV-2 infection and pathogenesis, and evaluate countermeasures against COVID-19 (9-11). Here we report the generation of a mouseadapted strain of SARS-CoV-2 that can productively replicate in the respiratory tract, and cause interstitial pneumonia in wild-type immunocompetent mice. Additionally, the protective efficacy of a newly developed recombinant subunit vaccine candidate based on SARS-CoV-2 RBD was assayed using this mouse challenge model. 


\section{Results}

\section{Rapid adaption of SARS-CoV-2 in BALB/c mice}

To generate a SARS-CoV-2 mouse-adapted strain, the human clinical isolate of SARS-CoV-2 (BetaCov/human/CHN/Beijing_IME-BJ05/2020, abbreviated as IMEBJ05) was serially passaged by intranasal (i.n.) inoculation in aged mice (Fig. 1A), as previously described for SARS-CoV (12). Briefly, nine-month-old BALB/c mice were intranasally inoculated with $7.2 \times 10^{5}$ plaque forming unit (PFU) of SARS$\mathrm{CoV}-2$, and the lung tissues were collected from each passage for viral RNA load analysis at 3 days post-inoculation (dpi). Interestingly, substantial viral RNAs $\left(10^{8.32}\right.$ copies/g) were readily detected after a single passage, which was defined as passage 0 (P0), in the lung homogenate (Fig. 1B). Subsequently, the viral RNA copies in the lung approached $10^{10.68}$ RNA copies/g at passage 3 (P3), which was about 250 -fold higher than those at P0, and remained at a similar level during the following passages (Fig. 1B). The final viral stock at passage 6 (P6) was titrated by plaque assays (fig. S1A) and termed as MASCp6 for further characterization.

To determine whether the increased viral RNA loads in mouse lungs could be attributed to the enhanced infectivity of the virus in mice, we examined the replication kinetics and tissue tropism of MASCp6 in both aged (nine-month-old) and young (six-week-old) BALB/c mice. Following intranasal inoculation with $1.6 \times 10^{4} \mathrm{PFU}$ of MASCp6, high level of viral RNAs in the lungs and tracheas were detected at 3,5 and 7 dpi in all aged mice (Fig. 1C) with peak viral RNA loads of $\sim 10^{10}$ copies/g at $3 \mathrm{dpi}$, which was comparable to the results from the human ACE2 transgenic mice (10). Viral RNAs were also detected in heart, liver, spleen, and brain, as well as in feces. Marginal viral RNA was detected in the kidney and serum from individual infected mice (Fig. 1C). Similar tissue distribution of SARS-CoV-2 RNA was also seen in the MASCp6-infected young mice (Fig. 1C). Immunostaining of lung section from MASCp6-infected mice showed robust expression of $\mathrm{S}$ protein along the airways and at the alveolus in both young and aged mice at 3 and 5 dpi (fig. S1B). To identify the major cell types infected by SARS-CoV-2 in our model, lung sections were further analyzed by multiplex immunofluorescence staining for SARS-CoV-2 S protein and specific lung epithelium cell markers. As shown in Fig. 1D, co-localization of $\mathrm{CC}^{+} 0^{+}$club cells and SARS-CoV-2 S protein were observed predominantly in the bronchi and bronchioles, as well as the bronchioalveolar-duct junction (BADJ) of the lungs. Furthermore, $\mathrm{SPC}^{+}$alveolar type 2 (AT2) cells were also costained with $\mathrm{S}$ protein in the BADJ and alveoli. However, SARS-CoV-2 $S$ protein was not detected in all $\beta$-IV-tubulin ${ }^{+}$ ciliated cells and PDPN ${ }^{+}$alveolar type 1 (AT1) cells. Thus, club cells and AT2 cells are the major target cells that support SARS-CoV-2 replication in mouse lung in our model.

\section{Characterization of MASCp6 infection in BALB/c mice}

To further characterize pathological features in the MASCp6-infected BALB/c mice, lung tissues were collected at 3 or 5 dpi, respectively, and subjected to histopathological analysis by Hematoxylin and eosin (H\&E) staining. Both aged and young $\mathrm{BALB} / \mathrm{c}$ mice presented with mild to moderate pneumonia after MASCp6 infection (Fig. 2, A and C). In the aged mice, MASCp6 infection caused interstitial pneumonia at $3 \mathrm{dpi}$, characterized with denatured and collapsed epithelial cells, thickened alveolar septa, alveolar damage, focal exudation and hemorrhage, and activated inflammatory cell infiltration. Vessels were obviously injured, with adherent inflammatory cells and damaged basement membrane (Fig. $2 \mathrm{~A})$. At $5 \mathrm{dpi}$, the lung damage was much milder than that seen at 3 dpi (Fig. 2A), suggesting a self-recovering process. In addition, multiplex immunofluorescence staining demonstrated that SARS-CoV-2 infection led to massive cell death, as evidenced by cleaved caspase- 3 staining, at $3 \mathrm{dpi}$, as well as significant inflammatory cell infiltration in $\mathrm{CD} 103^{+}$dendritic cells, $\mathrm{CD}_{163^{+}}$macrophages, and $\mathrm{CD}^{+} \mathrm{T}$ lymphocytes in the lung of aged mice (fig. S2A). Importantly, serum concentrations of inflammatory cytokines, including IL-1 $\beta$, IL- 6 , and IL-5, were up-regulated upon MASCp6 challenge (Fig. 2B and fig. S3A). As expected, the young mice developed similar, but much milder lung damage than the aged mice following MASCp6 challenge (Fig. 2C). Similarly, inflammatory cell infiltration (fig. S2B) and serum cytokine response (Fig. 2D and fig.S3B) in the young mice was much weaker than that of aged mice. Additionally, MASCp6 infection caused no significant changes in the body weight of aged or young mice (fig. S4). Taken together, these results demonstrate that MASCp6 can productively replicate in the lower respiratory tract of wild type BALB/c mice, resulting in a more severe interstitial pneumonia phenotype in the aged mice.

\section{Identification of adaptive mutations that emerged in MSACp 6}

To decipher the underlying mechanism for the increased virulence of MASCp6, the complete genome of MASCp6 was subjected to deep sequencing by an Ion Torrent S5Plus sequencer. Compared with the full genome of the original SARS-CoV-2 strain IME-BJ05, MASCp6 contains five nucleotide mutations which are distributed within the ORFlab, S, and $\mathrm{N}$ gene, respectively (Fig. 3A and table S1). The A23063T mutation resulted in a N501Y amino acid substitution in the $\mathrm{RBD}$ of the $\mathrm{S}$ protein, which is assumed to be responsible for receptor recognition and host range of SARS-CoV-2 $(13,14)$. Structural remodeling also suggested that the N501Y substitution in the RBD of SARS-CoV S protein increased the binding affinity of the protein to mouse ACE2 (Fig. 3B). Immunofluorescence staining supported colocalization of 
mouse ACE2 and SARS-CoV-2 $\mathrm{S}$ protein in the lungs of MASCp6 infected mice (Fig. 3C). To further trace the adaption history of MASCp6, the emergence of N501Y substitution was further analyzed by deep sequencing. As expected, all reads from the original IME-BJ05 isolate were pure A23063. Strikingly, T23063 readily emerged after a single passage in one of the three mouse lung homogenates (table S2), and the proportion of A23063T mutation gradually increased during subsequent passages (Fig. 3D). Thus, the increased virulence of SARS-CoV-2 MASCp6 in mice was likely attributed to the rapid emergence of N501Y substitution in the RBD of SARSCoV-2 S protein.

\section{Validation of the protective efficacy of an RBD-based SARS-CoV-2 subunit vaccine}

To validate the utility of this novel mouse challenge model, we tested the protection efficacy of a recombinant subunit vaccine candidate against COVID-19. Briefly, SARSCoV-2 RBD (aa 331-524) fused with a human IgG Fc at the Cterminal (fig. S5A) was expressed in $\mathrm{CHO}-\mathrm{K} 1$ cells, and purified by affinity chromatography and anion exchange chromatography in a GLP lab. As expected, the molecular weight of recombinant RBD-Fc was about $47.98 \mathrm{KD}$, as detected by mass spectroscopy (fig. S4B), and flow cytometry analysis confirmed that RBD-Fc, not the Fc control, specifically bound to human ACE2 expressed in the stable ACE2/293T cells (fig. S4C) (15).

Female BALB/c mice were then subcutaneously (s.c.) immunized with two doses of recombinant RBD-Fc (10 $\mu \mathrm{g} /$ mouse) at a 2-week interval, and mice immunized with PBS were set as controls. As expected, high levels of SARSCoV-2 specific IgG antibodies (Fig. 4A) and neutralization antibodies (Fig. 4B) were elicited in all the RBD-Fc immunized mice at 2 weeks post boost immunization. All immunized mice were then intranasally challenged with MASCp6 $\left(1.6 \times 10^{4} \mathrm{PFU}\right)$, and lung tissues were collected for virological and histopathological analysis at 5 days post challenge. As expected, all the PBS-treated mice sustained high level of viral RNA loads in the lung at 5 days post-challenge. In contrast, a significant reduction in viral RNA loads (approximately 1,000-fold) were seen in the lung of RBD-Fc immunized mice compared with the control animals (Fig. 4C). Moreover, immunofluorescence staining for SARS-CoV$2 \mathrm{~S}$ protein showed that only a small population of positive cells was detected in the lung from the RBD-Fc immunized mice, whereas abundant viral proteins were seen in the lung from PBS-immunized mice (Fig. 4D). Importantly, no apparent pathological damage was observed in the lung of RBD-Fc immunized mice, whereas inflammatory lung injury, with focal perivascular and peribronchiolar inflammation, as well as thickened alveolar septa, were found in the lung of the control mice (Fig. 4E). Taken together, these data indicate that our newly developed mouse model with MASCp6 represents a useful tool for testing the efficacy of COVID-19 vaccine candidates.

\section{Discussion}

An ideal animal model for COVID-19 should reproduce the viral replication as well as the clinical outcome observed in COVID-19 patients. Here we report the rapid adaption of SARS-CoV-2 in BALB/c mice, and the resulting MASCp6 strain not only replicated efficiently in the trachea and lung, but also caused interstitial pneumonia and inflammatory responses, reproducing many clinical features observed in COVID-19 patients $(16,17)$. Upon MASCp6 challenge, SARSCoV-2 primarily replicated in the respiratory tracts, and viral RNAs peaked in the lungs at $3 \mathrm{dpi}$, and then decayed at 5 and 7 dpi. This result was consistent with other transgenic or humanized mouse models $(9,11)$. Of particular note, the aged mice developed more severe lung damage when compared with the young mice upon MASCp6 challenge, which reflects the fact that the mortality and fatality of COVID-19 are strongly skewed toward the elderly (18). Fatality was only reported by Jiang et al. (10) in SARS-CoV-2 infected ACE2 transgenic mice. In our challenge model, neither visible clinical symptoms nor body weight loss were recorded throughout the experiments (fig. S4). Of note, the challenge dose used in our experiment was $1.6 \times 10^{4} \mathrm{PFU}$, thus whether a higher challenge dose of MASCp6 would exacerbate the pathology remains to be determined.

The development of a mouse-adapted strain based challenge model has been well demonstrated in SARS-CoV and MERS-CoV studies $(12,19,20)$. Serial passaging of virus in mouse lungs results in adaptive mutations that increase viral infectivity. The MASCp6 genome contains five mutations in comparison to its parental strain IME-BJ05, and these mutations resulted in four amino acid residue changes in the ORF1ab, S and N genes, respectively (Fig. 3A). The N501Y mutation seems to provide a more favorable interaction with mouse ACE2 for docking and entry, thus leading to the increased virulence phenotype in mice. Whether the other three mutations, except for N501Y, also regulated viral infectivity remains to be determined. Further investigation with reverse genetics will clarify this issue and could allow the rapid synthesis of a recombinant SARS-CoV-2 with enhanced virulence $(21,22)$. Additionally, immunostaining results showed that lung club and AT2 cells are major target cells of MASCp6, which is in agreement with previous findings from animal models and COVID-19 patients (11, 23, 24).

Compared with the previously described ACE2 transgenic or humanized mice, our MASCp6-based challenge model employs immunocompetent wild-type mice, and can be directly applied to the efficacy evaluation of various vaccine candidates. Immunization with the recombinant subunit vaccine 
candidate (RBD-Fc) induced high levels (up to 1:320) of neutralizing antibodies against SARS-CoV-2, nearly eliminating viral RNA replication in mouse lungs following MASCp6 challenge (Fig. 4, B and C). The potential correlation between serum neutralizing antibody titers in the vaccinated mice and the protective efficacy highlights the versatility of this convenient and economical animal model. Recently, non-human primates, which are closest to humans phylogenetically, have also been used to reproduce SARS-CoV-2 infection, and several vaccine candidates have been validated with promising protection efficacy (25-27). Hamsters, ferrets and cats are also permissive to SARS-CoV-2 infection (28-30), and the clinical outcome varies from asymptomatic infection to severe pathological lung lesions following SARS-CoV-2 infection. No single animal model for SARS-CoV-2 currently reproduces all aspects of the human disease. Therefore the establishment of different animal models should greatly expand our understanding of SARS-CoV-2 transmission and pathogenesis and accelerate the development of countermeasures against COVID-19.

\section{REFERENCES AND NOTES}

1. P. Zhou, X.-L. Yang, X.-G. Wang, B. Hu, L. Zhang, W. Zhang, H.-R. Si, Y. Zhu, B. Li, C.L. Huang, H.-D. Chen, J. Chen, Y. Luo, H. Guo, R.-D. Jiang, M.-Q. Liu, Y. Chen, X.-R. Shen, X. Wang, X.-S. Zheng, K. Zhao, Q.-J. Chen, F. Deng, L.-L. Liu, B. Yan, F.-X. Zhan, Y.-Y. Wang, G.-F. Xiao, Z.-L. Shi, A pneumonia outbreak associated with a new coronavirus of probable bat origin. Nature 579, 270-273 (2020). doi:10.1038/s41586-020-2012-7 Medline

2. L. F. Moriarty, M. M. Plucinski, B. J. Marston, E. V. Kurbatova, B. Knust, E. L. Murray, N. Pesik, D. Rose, D. Fitter, M. Kobayashi, M. Toda, P. T. Cantey, T. Scheuer, E. S. Halsey, N. J. Cohen, L. Stockman, D. A. Wadford, A. M. Medley, G. Green, J. J. Regan, K. Tardivel, S. White, C. Brown, C. Morales, C. Yen, B. Wittry, A. Freeland, S. Naramore, R. T. Novak, D. Daigle, M. Weinberg, A. Acosta, C. Herzig, B. K. Kapella, K. R. Jacobson, K. Lamba, A. Ishizumi, J. Sarisky, E. Svendsen, T. Blocher, C. Wu, J. Charles, R. Wagner, A. Stewart, P. S. Mead, E. Kurylo, S. Campbell, R. Murray, P. Weidle, M. Cetron, C. R. Friedman, C. B. Behravesh, A. Bjork, W. Bower, C. Bozio, Z. Braden, M. C. Bertulfo, K. Chatham-Stephens, V. Chu, B. Cooper, K. Dooling, C. Dubray, E. Curren, M. A. Honein, K. Ivey, J. Jones, M. Kadzik, N. Knight, M. Marlow, A. McColloch, R. McDonald, A. Klevos, S. Poser, R. A. Rinker, T. Ritter, L. Rodriguez, M. Ryan, Z. Schneider, C. Shockey, J. Shugart, M. Silver, P. W. Smith, F. Tobolowsky, A. Treffiletti, M. Wallace, J. Yoder, P. Barry, R. Berumen III, B. Bregman, K. Campos, S. Chai, R. Glenn-Finer, H. Guevara, J. Hacker, K. Hsieh, M. K. Morris, R. Murphy, J. F. Myers, T. Padilla, C.-Y. Pan, A. Readhead, E. Saguar, M. Salas, R. E. Snyder, D. Vugia, J. Watt, C. Wong, M. Acosta, S. Davis, B. Kapuszinsky, B. Matyas, G. Miller, A. Ntui, J. Richards, CDC Cruise Ship Response Team, California Department of Public Health COVID-19 Team, Solano County COVID-19 Team, Public Health Responses to COVID-19 Outbreaks on Cruise Ships Worldwide, February-March 2020. MMWR Morb. Mortal. Wkly. Rep. 69, 347-352 (2020). doi:10.15585/mmwr.mm6912e3 Medline

3. N. Zhu, D. Zhang, W. Wang, X. Li, B. Yang, J. Song, X. Zhao, B. Huang, W. Shi, R. Lu, P. Niu, F. Zhan, X. Ma, D. Wang, W. Xu, G. Wu, G. F. Gao, W. Tan; China Novel Coronavirus Investigating and Research Team, A Novel Coronavirus from Patients with Pneumonia in China, 2019. N. Engl. J. Med. 382, 727-733 (2020). doi:10.1056/NEJMoa2001017 Medline

4. N. Vabret, G. J. Britton, C. Gruber, S. Hegde, J. Kim, M. Kuksin, R. Levantovsky, L. Malle, A. Moreira, M. D. Park, L. Pia, E. Risson, M. Saffern, B. Salomé, M. Esai Selvan, M. P. Spindler, J. Tan, V. van der Heide, J. K. Gregory, K. Alexandropoulos, N. Bhardwaj, B. D. Brown, B. Greenbaum, Z. H. Gümüş, D. Homann, A. Horowitz, A. O. Kamphorst, M. A. Curotto de Lafaille, S. Mehandru, M. Merad, R. M. Samstein, M. Agrawal, M. Aleynick, M. Belabed, M. Brown, M. Casanova-Acebes, J. Catalan, M. Centa, A. Charap, A. Chan, S. T. Chen, J. Chung, C. C. Bozkus, E. Cody, F.
Cossarini, E. Dalla, N. Fernandez, J. Grout, D. F. Ruan, P. Hamon, E. Humblin, D. Jha, J. Kodysh, A. Leader, M. Lin, K. Lindblad, D. Lozano-Ojalvo, G. Lubitz, A. Magen, Z. Mahmood, G. Martinez-Delgado, J. Mateus-Tique, E. Meritt, C. Moon, J. Noel, T. O'Donnell, M. Ota, T. Plitt, V. Pothula, J. Redes, I. Reyes Torres, M. Roberto, A. R. Sanchez-Paulete, J. Shang, A. S. Schanoski, M. Suprun, M. Tran, N. Vaninov, C. M. Wilk, J. Aguirre-Ghiso, D. Bogunovic, J. Cho, J. Faith, E. Grasset, P. Heeger, E. Kenigsberg, F. Krammer, U. Laserson, Sinai Immunology Review Project, Immunology of COVID-19: Current State of the Science. Immunity 52, 910-941 (2020). doi:10.1016/j.immuni.2020.05.002 Medline

5. Y. He, H. Lu, P. Siddiqui, Y. Zhou, S. Jiang, Receptor-binding domain of severe acute respiratory syndrome coronavirus spike protein contains multiple conformationdependent epitopes that induce highly potent neutralizing antibodies. J. Immunol. 174, 4908-4915 (2005). doi:10.4049/jimmunol.174.8.4908 Medline

6. L. Du, G. Zhao, Z. Kou, C. Ma, S. Sun, V. K. M. Poon, L. Lu, L. Wang, A. K. Debnath, B.-J. Zheng, Y. Zhou, S. Jiang, Identification of a receptor-binding domain in the S protein of the novel human coronavirus Middle East respiratory syndrome coronavirus as an essential target for vaccine development. J. Virol. 87, 99399942 (2013). doi:10.1128/JVI.01048-13 Medline

7. L. Du, G. Zhao, Y. He, Y. Guo, B.-J. Zheng, S. Jiang, Y. Zhou, Receptor-binding domain of SARS-CoV spike protein induces long-term protective immunity in an animal model. Vaccine 25, 2832-2838 (2007). doi:10.1016/j. vaccine.2006.10.031 Medline

8. L. Du, Y. He, Y. Zhou, S. Liu, B.-J. Zheng, S. Jiang, The spike protein of SARS-CoVA target for vaccine and therapeutic development. Nat. Rev. Microbiol. 7, 226-236 (2009). doi:10.1038/nrmicro2090 Medline

9. L. Bao, W. Deng, B. Huang, H. Gao, J. Liu, L. Ren, Q. Wei, P. Yu, Y. Xu, F. Qi, Y. Qu, F. Li, Q. Lv, W. Wang, J. Xue, S. Gong, M. Liu, G. Wang, S. Wang, Z. Song, L. Zhao, P. Liu, L. Zhao, F. Ye, H. Wang, W. Zhou, N. Zhu, W. Zhen, H. Yu, X. Zhang, L. Guo, L. Chen, C. Wang, Y. Wang, X. Wang, Y. Xiao, Q. Sun, H. Liu, F. Zhu, C. Ma, L. Yan, M. Yang, J. Han, W. Xu, W. Tan, X. Peng, Q. Jin, G. Wu, C. Qin, The pathogenicity of SARS-CoV-2 in hACE2 transgenic mice. Nature (2020). doi:10.1038/s41586-0202312-y Medline

10. R. D. Jiang, M.-Q. Liu, Y. Chen, C. Shan, Y.-W. Zhou, X.-R. Shen, Q. Li, L. Zhang, Y. Zhu, H.-R. Si, Q. Wang, J. Min, X. Wang, W. Zhang, B. Li, H.-J. Zhang, R. S. Baric, P. Zhou, X.-L. Yang, Z.-L. Shi, Pathogenesis of SARS-CoV-2 in Transgenic Mice Expressing Human Angiotensin-Converting Enzyme 2. Cell 182, 50-58.e8 (2020). doi:10.1016/i.cell.2020.05.027 Medline

11. S. H. Sun, Q. Chen, H.-J. Gu, G. Yang, Y.-X. Wang, X.-Y. Huang, S.-S. Liu, N.-N. Zhang, X.-F. Li, R. Xiong, Y. Guo, Y.-Q. Deng, W.-J. Huang, Q. Liu, Q.-M. Liu, Y.-L. Shen, Y. Zhou, X. Yang, T.-Y. Zhao, C.-F. Fan, Y.-S. Zhou, C.-F. Qin, Y.-C. Wang, A Mouse Model of SARS-CoV-2 Infection and Pathogenesis. Cell Host Microbe 28, 124-133.e4 (2020). doi:10.1016/i.chom.2020.05.020 Medline

12. A. Roberts, D. Deming, C. D. Paddock, A. Cheng, B. Yount, L. Vogel, B. D. Herman, T. Sheahan, M. Heise, G. L. Genrich, S. R. Zaki, R. Baric, K. Subbarao, A mouseadapted SARS-coronavirus causes disease and mortality in BALB/c mice. PLOS Pathog. 3, e5 (2007). doi:10.1371/journal.ppat.0030005 Medline

13. Y. Wang, M. Liu, J. Gao, Enhanced receptor binding of SARS-CoV-2 through networks of hydrogen-bonding and hydrophobic interactions. Proc. Natl. Acad. Sci. U.S.A. 117, 13967-13974 (2020). doi:10.1073/pnas.2008209117Medline

14. C. Yi, X. Sun, J. Ye, L. Ding, M. Liu, Z. Yang, X. Lu, Y. Zhang, L. Ma, W. Gu, A. Qu, J. Xu, Z. Shi, Z. Ling, B. Sun, Key residues of the receptor binding motif in the spike protein of SARS-CoV-2 that interact with ACE2 and neutralizing antibodies. Cell. Mol. Immunol. 17, 621-630 (2020). doi:10.1038/s41423-020-0458-z Medline

15. W. Tai, L. He, X. Zhang, J. Pu, D. Voronin, S. Jiang, Y. Zhou, L. Du, Characterization of the receptor-binding domain (RBD) of 2019 novel coronavirus: Implication for development of RBD protein as a viral attachment inhibitor and vaccine. Cell. Mol. Immunol. 17, 613-620 (2020). doi:10.1038/s41423-020-0400-4 Medline

16. E. M. Dufort, E. H. Koumans, E. J. Chow, E. M. Rosenthal, A. Muse, J. Rowlands, M. A. Barranco, A. M. Maxted, E. S. Rosenberg, D. Easton, T. Udo, J. Kumar, W. Pulver, L. Smith, B. Hutton, D. Blog, H. Zucker; New York State and Centers for Disease Control and Prevention Multisystem Inflammatory Syndrome in Children Investigation Team, Multisystem Inflammatory Syndrome in Children in New York State. N. Engl. J. Med. 383, 347-358 (2020). doi:10.1056/NEJMoa2021756 Medline 
17. L. Carsana, A. Sonzogni, A. Nasr, R. S. Rossi, A. Pellegrinelli, P. Zerbi, R. Rech, R. Colombo, S. Antinori, M. Corbellino, M. Galli, E. Catena, A. Tosoni, A. Gianatti, M. Nebuloni, Pulmonary post-mortem findings in a series of COVID-19 cases from northern Italy: A two-centre descriptive study. Lancet Infect. Dis. S14733099(20)30434-5 (2020). doi:10.1016/S1473-3099(20)30434-5 Medline

18. E. Petersen, M. Koopmans, U. Go, D. H. Hamer, N. Petrosillo, F. Castelli, M. Storgaard, S. Al Khalili, L. Simonsen, Comparing SARS-CoV-2 with SARS-CoV and influenza pandemics. Lancet Infect. Dis. S1473-3099(20)30484-9 (2020). doi:10.1016/S1473-3099(20)30484-9 Medline

19. M. Frieman, B. Yount, S. Agnihothram, C. Page, E. Donaldson, A. Roberts, L. Vogel, B. Woodruff, D. Scorpio, K. Subbarao, R. S. Baric, Molecular determinants of severe acute respiratory syndrome coronavirus pathogenesis and virulence in young and aged mouse models of human disease. J. Virol. 86, 884-897 (2012). doi:10.1128/JVI.05957-11 Medline

20. K. Li, P. B. McCray Jr., Development of a Mouse-Adapted MERS Coronavirus. Methods Mol. Biol. 2099, 161-171 (2020). doi:10.1007/978-1-0716-0211-9 13 Medline

21. X. Xie, A. Muruato, K. G. Lokugamage, K. Narayanan, X. Zhang, J. Zou, J. Liu, C. Schindewolf, N. E. Bopp, P. V. Aguilar, K. S. Plante, S. C. Weaver, S. Makino, J. W. LeDuc, V. D. Menachery, P.-Y. Shi, An Infectious cDNA Clone of SARS-CoV-2. Cell Host Microbe 27, 841-848.e3 (2020). doi:10.1016/i.chom.2020.04.004 Medline

22. K. H. Dinnon et al., A mouse-adapted SARS-CoV-2 model for the evaluation of COVID-19 medical countermeasures. bioRxiv 081497 [Preprint] 7 May 2020; https://doi.org/10.1101/2020.05.06.081497.

23. C. Wang, J. Xie, L. Zhao, X. Fei, H. Zhang, Y. Tan, X. Nie, L. Zhou, Z. Liu, Y. Ren, L. Yuan, Y. Zhang, J. Zhang, L. Liang, X. Chen, X. Liu, P. Wang, X. Han, X. Weng, Y. Chen, T. Yu, X. Zhang, J. Cai, R. Chen, Z.-L. Shi, X.-W. Bian, Alveolar macrophage dysfunction and cytokine storm in the pathogenesis of two severe COVID-19 patients. EBioMedicine 57, 102833 (2020). doi:10.1016/j.ebiom.2020.102833 Medline

24. K. P. Y. Hui, M.-C. Cheung, R. A. P. M. Perera, K.-C. Ng, C. H. T. Bui, J. C. W. Ho, M. M. T. Ng, D. I. T. Kuok, K. C. Shih, S.-W. Tsao, L. L. M. Poon, M. Peiris, J. M. Nicholls, M. C. W. Chan, Tropism, replication competence, and innate immune responses of the coronavirus SARS-CoV-2 in human respiratory tract and conjunctiva: An analysis in ex-vivo and in-vitro cultures. Lancet Respir. Med. 8, 687-695 (2020). doi:10.1016/S2213-2600(20)30193-4 Medline

25. W. Deng, L. Bao, J. Liu, C. Xiao, J. Liu, J. Xue, Q. Lv, F. Qi, H. Gao, P. Yu, Y. Xu, Y. Qu, F. Li, Z. Xiang, H. Yu, S. Gong, M. Liu, G. Wang, S. Wang, Z. Song, Y. Liu, W. Zhao, Y. Han, L. Zhao, X. Liu, Q. Wei, C. Qin, Primary exposure to SARS-CoV-2 protects against reinfection in rhesus macaques. Science eabc5343 (2020). doi:10.1126/science.abc5343 Medline

26. Q. Gao, L. Bao, H. Mao, L. Wang, K. Xu, M. Yang, Y. Li, L. Zhu, N. Wang, Z. Lv, H. Gao, X. Ge, B. Kan, Y. Hu, J. Liu, F. Cai, D. Jiang, Y. Yin, C. Qin, J. Li, X. Gong, X. Lou, W. Shi, D. Wu, H. Zhang, L. Zhu, W. Deng, Y. Li, J. Lu, C. Li, X. Wang, W. Yin, Y. Zhang, C. Qin, Development of an inactivated vaccine candidate for SARS-CoV-2. Science 369, 77-81 (2020). doi:10.1126/science. abc1932 Medline

27. J. Yu, L. H. Tostanoski, L. Peter, N. B. Mercado, K. McMahan, S. H. Mahrokhian, J. P. Nkolola, J. Liu, Z. Li, A. Chandrashekar, D. R. Martinez, C. Loos, C. Atyeo, S. Fischinger, J. S. Burke, M. D. Slein, Y. Chen, A. Zuiani, F. J. N Lelis, M. Travers, S. Habibi, L. Pessaint, A. Van Ry, K. Blade, R. Brown, A. Cook, B. Finneyfrock, A. Dodson, E. Teow, J. Velasco, R. Zahn, F. Wegmann, E. A. Bondzie, G. Dagotto, M. S. Gebre, X. He, C. Jacob-Dolan, M. Kirilova, N. Kordana, Z. Lin, L. F. Maxfield, F. Nampanya, R. Nityanandam, J. D. Ventura, H. Wan, Y. Cai, B. Chen, A. G. Schmidt, D. R. Wesemann, R. S. Baric, G. Alter, H. Andersen, M. G. Lewis, D. H. Barouch, DNA vaccine protection against SARS-CoV-2 in rhesus macaques. Science eabc6284 (2020). doi:10.1126/science. abc6284 Medline

28. J. Shi, Z. Wen, G. Zhong, H. Yang, C. Wang, B. Huang, R. Liu, X. He, L. Shuai, Z. Sun, Y. Zhao, P. Liu, L. Liang, P. Cui, J. Wang, X. Zhang, Y. Guan, W. Tan, G. Wu, H. Chen, Z. Bu, Susceptibility of ferrets, cats, dogs, and other domesticated animals to SARS-coronavirus 2. Science 368, 1016-1020 (2020). doi:10.1126/science.abb7015 Medline
29. Y. I. Kim, S.-G. Kim, S.-M. Kim, E.-H. Kim, S.-J. Park, K.-M. Yu, J.-H. Chang, E. J. Kim, S. Lee, M. A. B. Casel, J. Um, M.-S. Song, H. W. Jeong, V. D. Lai, Y. Kim, B. S. Chin, J.-S. Park, K.-H. Chung, S.-S. Foo, H. Poo, I.-P. Mo, O.-J. Lee, R. J. Webby, J. U. Jung, Y. K. Choi, Infection and Rapid Transmission of SARS-CoV-2 in Ferrets. Cell Host Microbe 27, 704-709.e2 (2020). doi:10.1016/j.chom.2020.03.023 Medline

30. S. F. Sia, L.-M. Yan, A. W. H. Chin, K. Fung, K.-T. Choy, A. Y. L. Wong, P. Kaewpreedee, R. A. P. M. Perera, L. L. M. Poon, J. M. Nicholls, M. Peiris, H.-L. Yen, Pathogenesis and transmission of SARS-CoV-2 in golden hamsters. Nature (2020). doi:10.1038/s41586-020-2342-5 Medline

\section{ACKNOWLEDGMENTS}

We thank Dr. X.D. Yu for excellent technical and biosafety support. Funding: This work was supported by the National Key Plan for Scientific Research and Development of China (No.2016YFD0500304, No.2016YFD0500306, No.2020YFA0707801), the National Natural Science Foundation of China (No.82041006 and 82041025), the National Science and Technology Major Project of China (No.2018ZX09711003, No.2017ZX10304402), and Beijing Municipal Science and Technology Project (No. Z201100001020004). C.F.Q. was supported by the National Science Fund for Distinguished Young Scholar (No.81925025), and the Innovative Research Group (No.81621005) from the NSFC, and the CAMS Innovation Fund for Medical Sciences (No.2019-12M-5049). Author contributions: H.G., Q.C., G.Y., L.H., H.F., Y.Q.D., Y.W., Y.T., Z.Z., Y.C., Y.L., X.F.L., J.L., N.Z., X.Y., S.C., G.Z., G.H., D.L., and Y.G. performed experiments; X.W., H.W., X.Y., Y.L., Y.H., Z.X., S.G., and X.S. analyzed data; Y.Z., and C.F.Q., conceived the project and designed the experiments. Y.Z., C.F.Q., and S.J. supervised the study and wrote the manuscript with the input of all coauthors. Competing interests: The authors declare no competing interests. Data and materials availability: The genome sequence of IME-BJ05 and MASCp 6 have been deposited in the Genome Warehouse in National Genomics Data Center (https://bigd.big.ac.cn/gwh), BIG, CAS, with the accession number of GWHACBBO1000000 and GWHACFH00000000, respectively. All requests for resources and reagents should be directed to Dr. Cheng-Feng Qin (qincf@bmi.ac.cn or qinlab313@163.com) and will be fulfilled after completion of a Materials Transfer Agreement. This work is licensed under a Creative Commons Attribution 4.0 International (CC BY 4.0) license, which permits unrestricted use, distribution, and reproduction in any medium, provided the original work is properly cited. To view a copy of this license, visit https://creativecommons.org/licenses/by/4.0/. This license does not apply to figures/photos/artwork or other content included in the article that is credited to a third party; obtain authorization from the rights holder before using such material.

\section{SUPPLEMENTARY MATERIALS}

science.sciencemag.org/cgi/content/full/science.abc4730/DC1

Materials and Methods

Figs S1 to S5

Tables S1 and S2

29 April 2020; resubmitted 29 May 2020

Accepted 15 July 2020

Published online 30 July 2020

10.1126/science.abc4730 
A

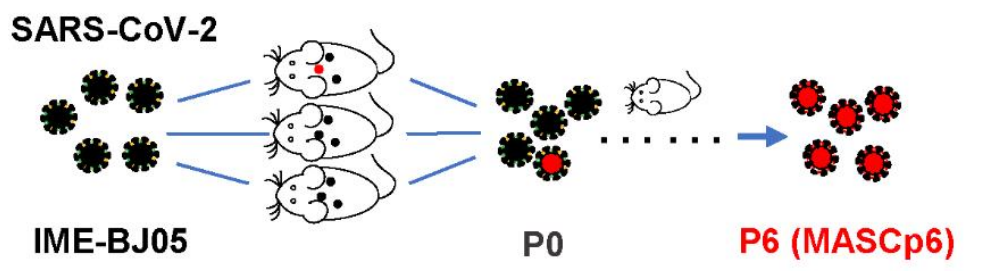

B

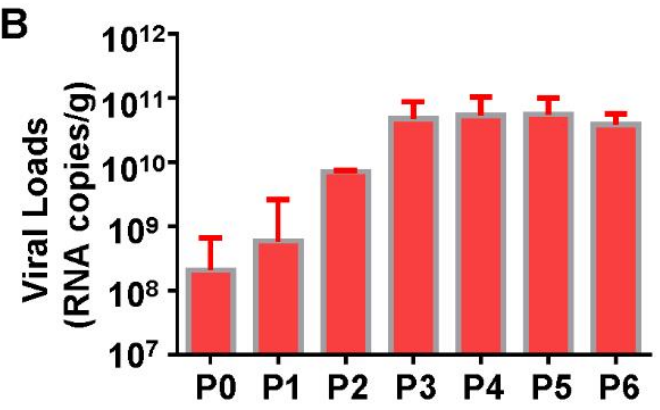

C
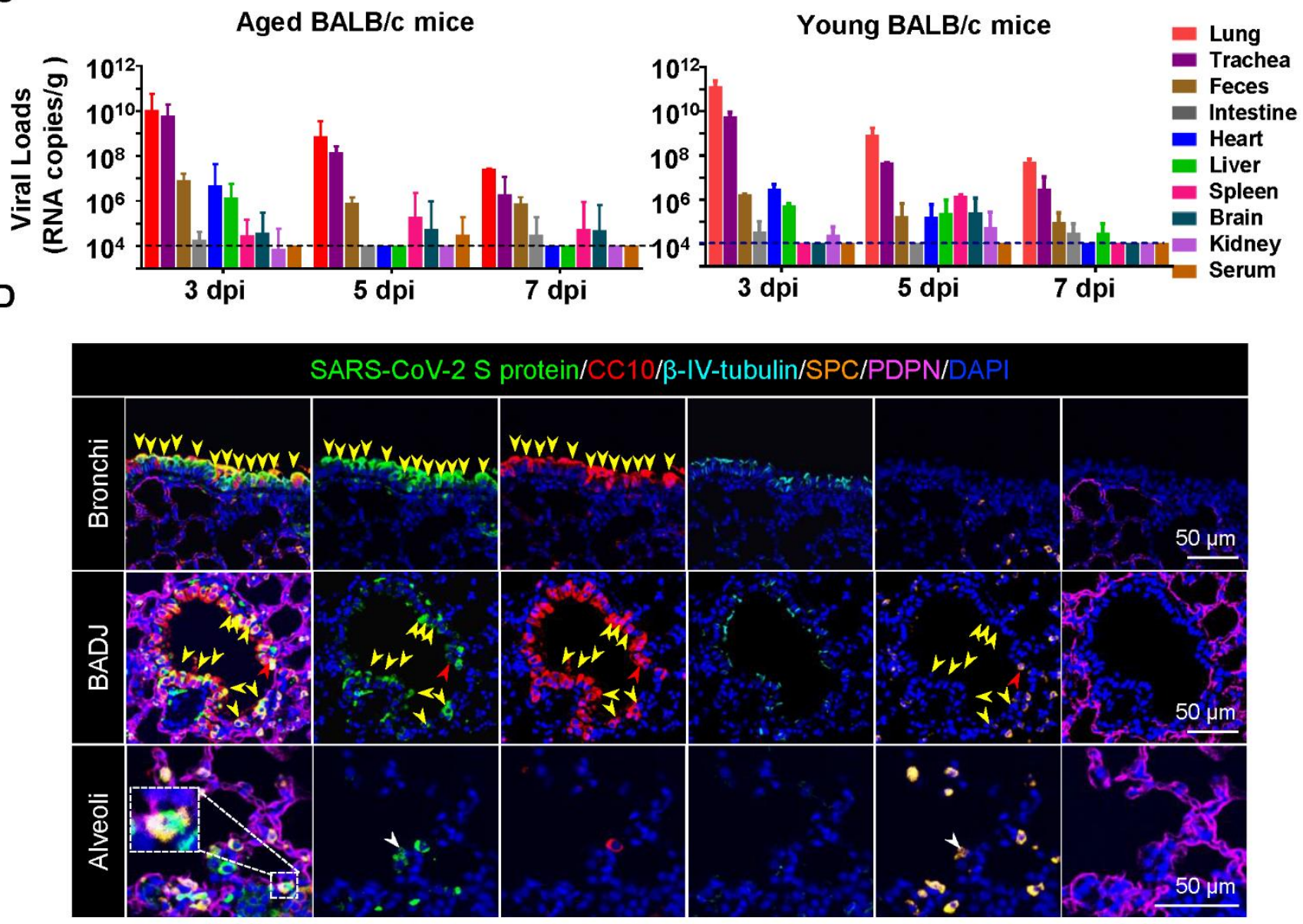

Fig. 1. Generation and characterization of a mouse-adapted strain of SARS-CoV-2 in BALB/c mice. (A) Schematic diagram of the passage history of SARS-CoV-2 in BALB/c mice. The original SARS-CoV-2 viruses are shown in black, and the adapted viruses in red. (B) SARS-CoV-2 genomic RNA loads in mouse lung homogenates at P0 to P6. Viral RNA copies were determined by RT-qPCR. Data are presented as means \pm standard error of the means (SEM) ( $n=2$ to 4). (C) Tissue distribution of SARS-CoV-2 viral RNAs in mice infected with MASCp6. Groups of aged and young mice were inoculated with $1.6 \times 10^{4} \mathrm{PFU}$ of MASCp6, and sacrificed at 3, 5, or $7 \mathrm{dpi}$, respectively. Feces, sera and the indicated tissue samples were collected at the specified times and subjected to viral RNA load analysis by RT-qPCR. Dash lines denote the detection limit. Data are presented as means \pm SEM $(n=3)$. (D) Multiplex immunofluorescence staining of mouse lung sections. SARS-CoV-2 S protein (green), CC1O (red), $\beta$-IVtubulin (cyan), PDPN (magenta), SPC (gold), and nuclei (blue). The dash box is magnified at the bottom right corner of the same image. Yellow arrow heads indicate SARS- $\mathrm{CoV}-2^{+} / \mathrm{CC} \mathrm{O}^{+}$cells, red arrow heads indicate SARS$\mathrm{CoV}-2^{+} / \mathrm{CC} 10^{+} / \mathrm{SPC}^{+}$cells, and the white arrow indicate SARS-CoV- $2^{+} / \mathrm{SPC}^{+}$cells. 
A

Aged mice

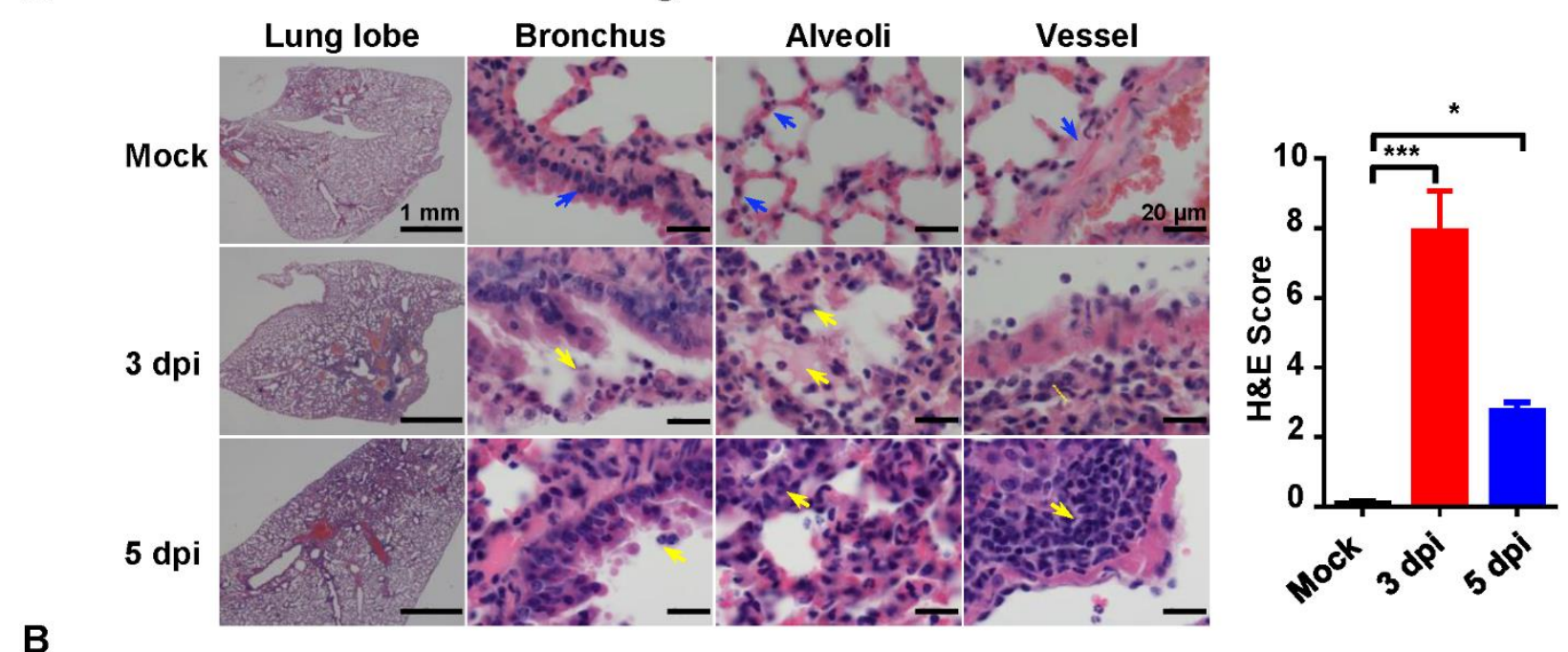

Mock

3 dpi

5 dpi

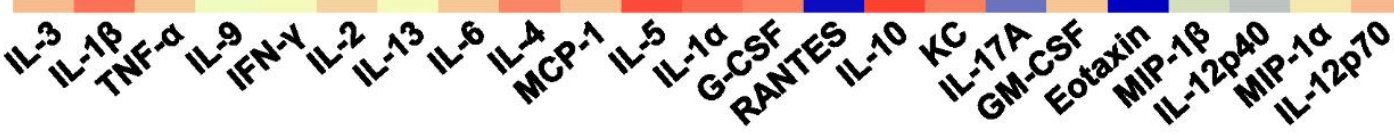

C

\section{Young mice}

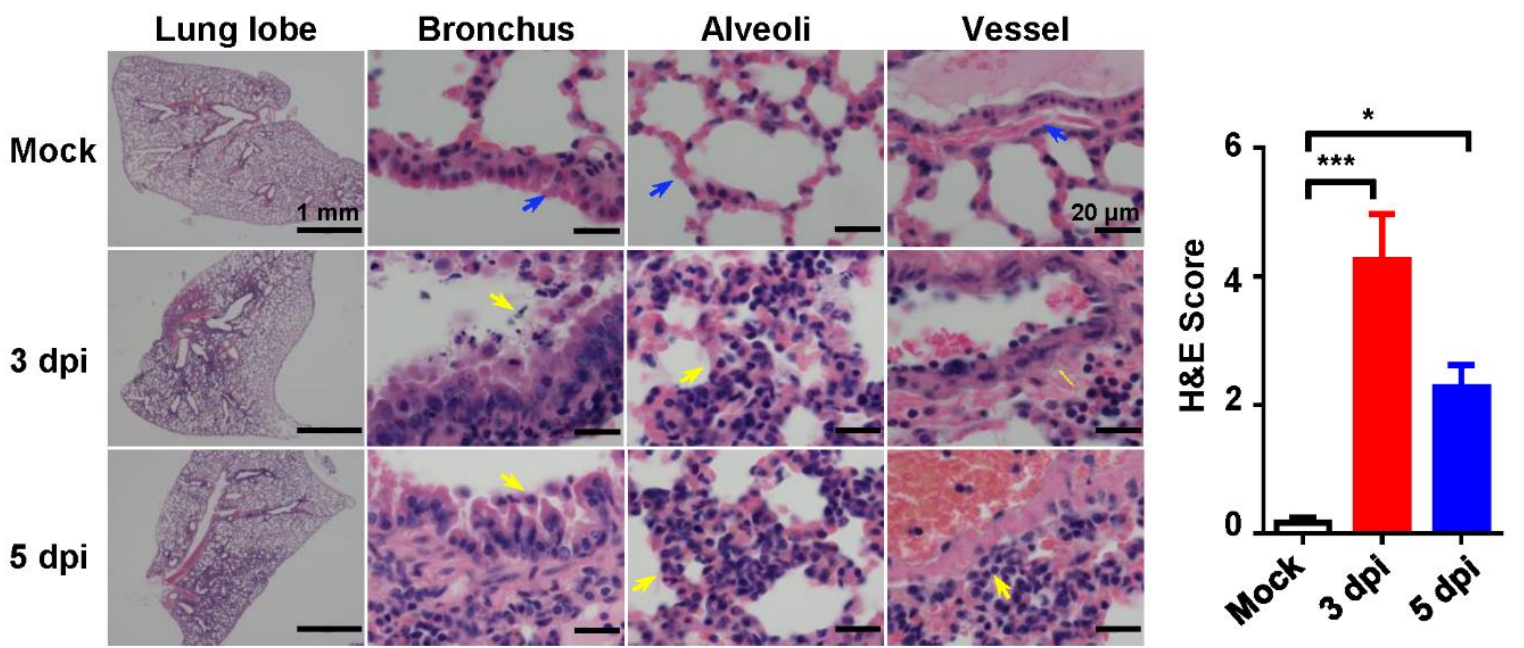

D
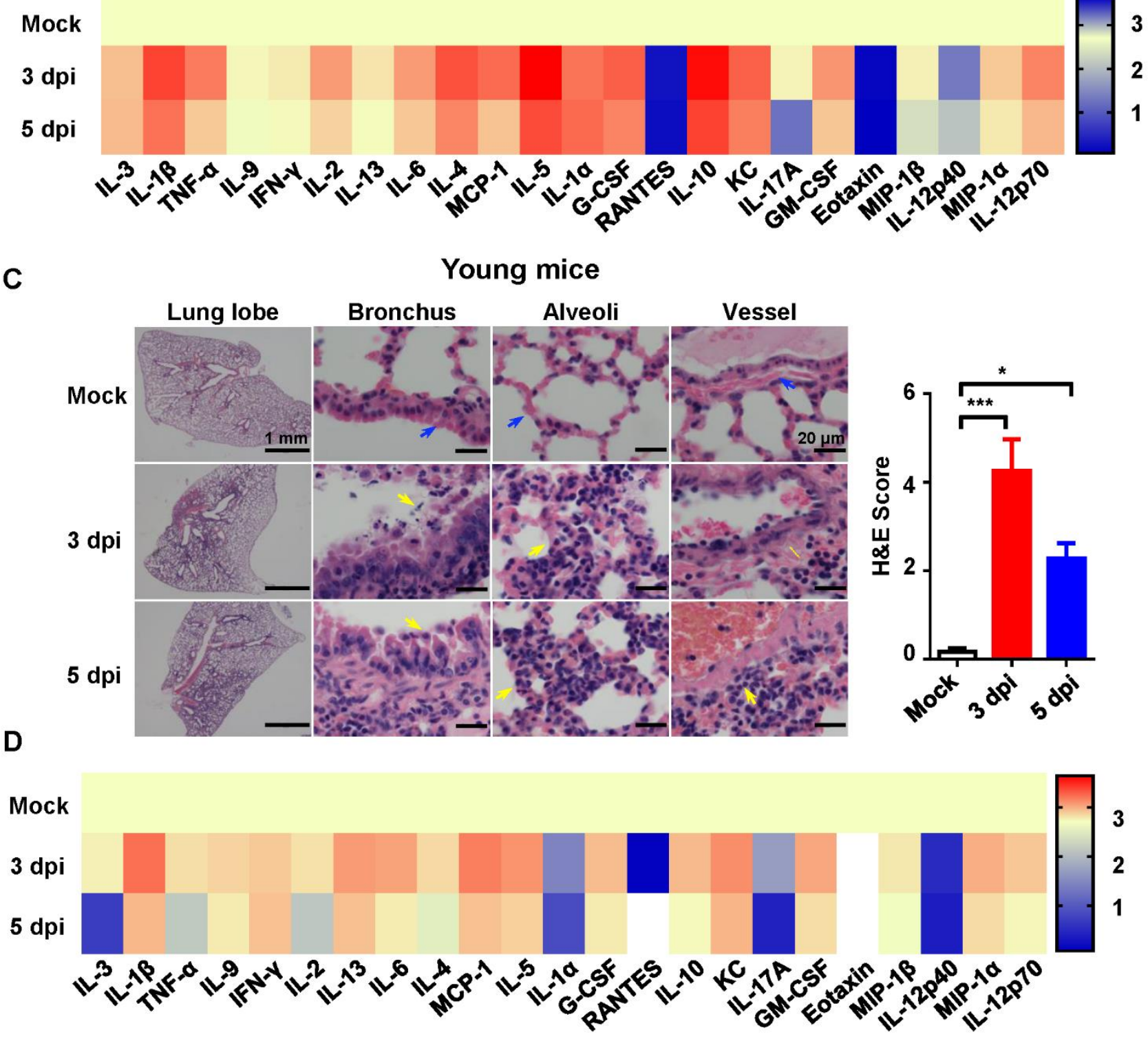
Fig. 2. MASCp6 infection causes pathological lung lesions and inflammatory responses in both aged and young BALB/c mice. (A) Hematoxylin and eosin (H\&E) staining of lung sections from aged (9-month-old) BALB/c mice infected with MASCp6. Blue arrows indicate the normal areas, and yellow arrows indicate damaged areas. Data from semiquantitative analysis of histopathological changes of lung tissues are presented as means $\pm \operatorname{SEM}(n=3)$. Statistical significance was analyzed by Mann-Whitney test. (B) Serum cytokine and chemokine heatmap in MASCp6-infected aged mice. Data are presented as fold change relative to mock infection $(n=5)$. (C) H\&E staining of lung sections from MASCp6-infected young mice $(n=3)$. (D) Serum cytokine and chemokine heatmap in MASCp6-infected young mice $(n=5) .{ }^{*} P<0.05,{ }^{* * *} P<0.001$. 

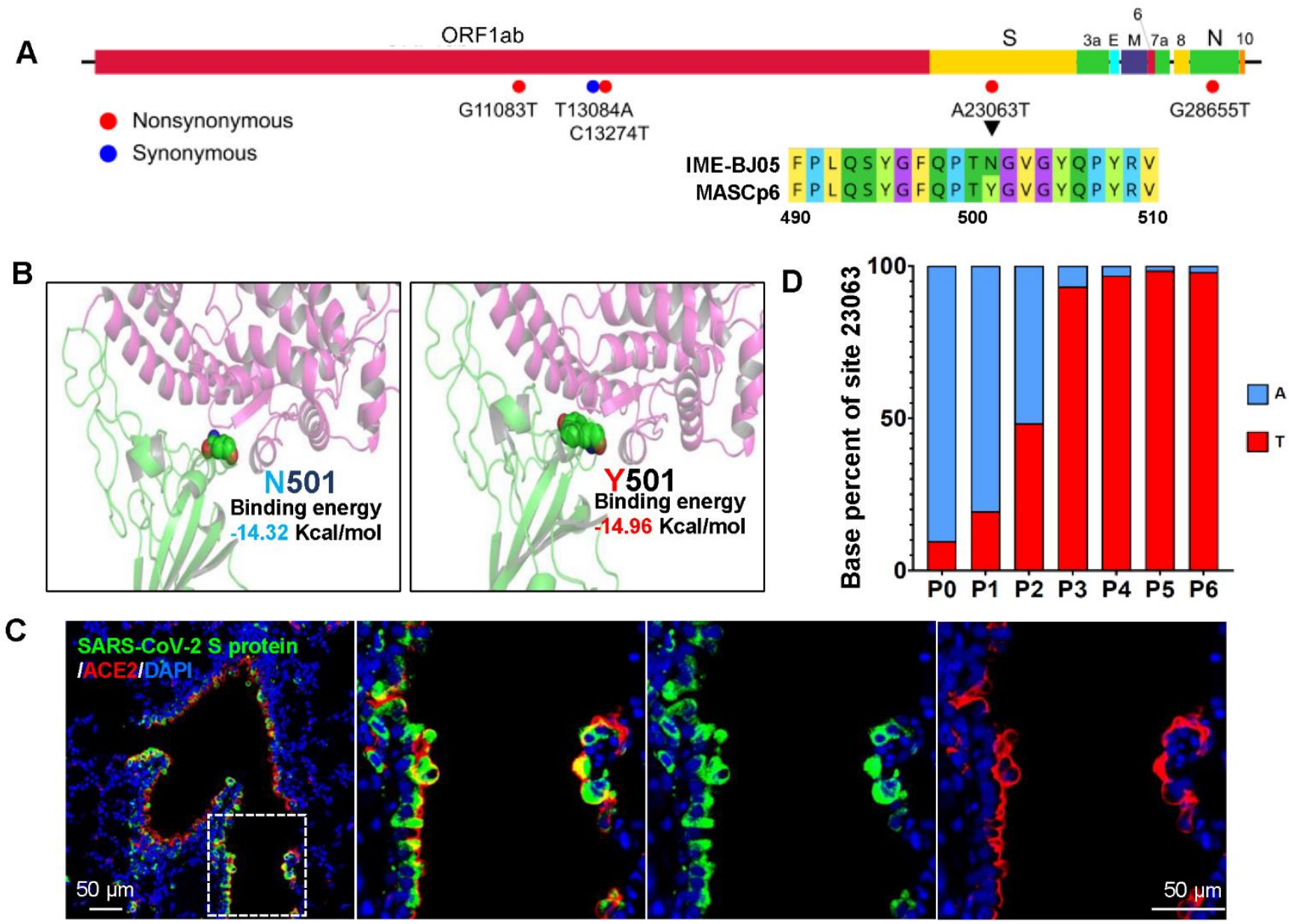

Fig. 3. MASCp6 carries a unique amino acid substitution in the RBD of the Spike (S) protein. (A) Schematic diagram of SARS-CoV-2 genome and all the adaptive mutations identified in MASCp6. Amino acid sequences of the parental IME-BJ05 strain and the MASCp6 strain adjacent to the N501Y mutation are shown. (B) Homology modeling of mouse ACE2 (pink) in complex with SARS-CoV-2 RBD (green) with N501 (left) or Y501 residue (right). (C) Colocalization of SARS-CoV-2 S protein (green) and mouse ACE2 (red) in the lung from SARS-CoV-2 infected mice. The dash box in the left image is magnified in the three images at the right. (D) The proportion of A23063T mutation in each passage. The mutation threshold was defined as $1 \%$ according to the average quality score of sequenced base. 
A

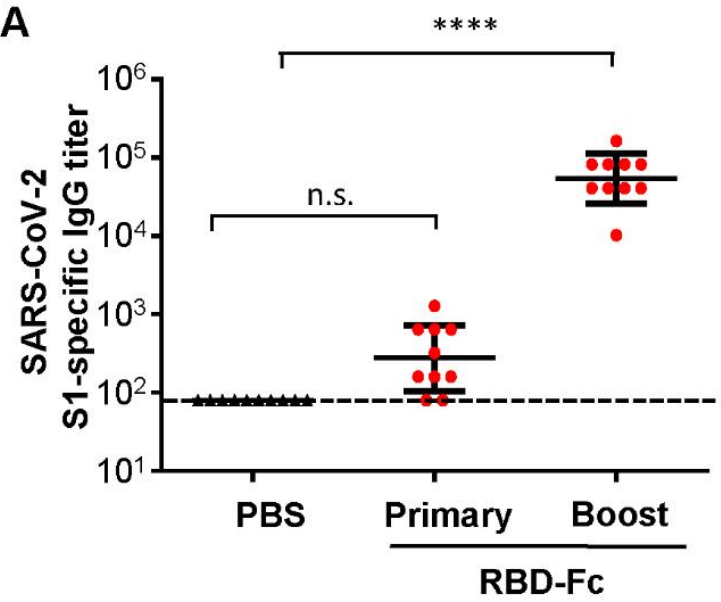

B

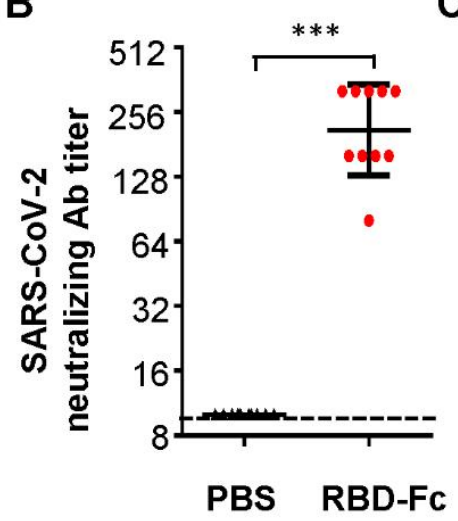

C

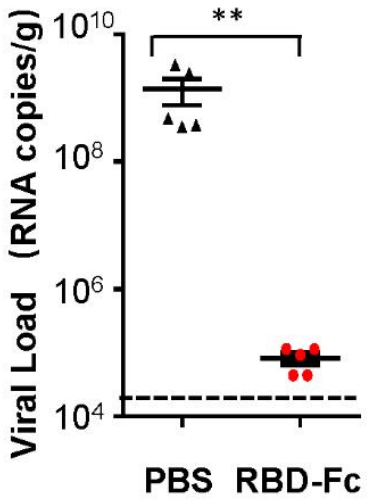

D PBS

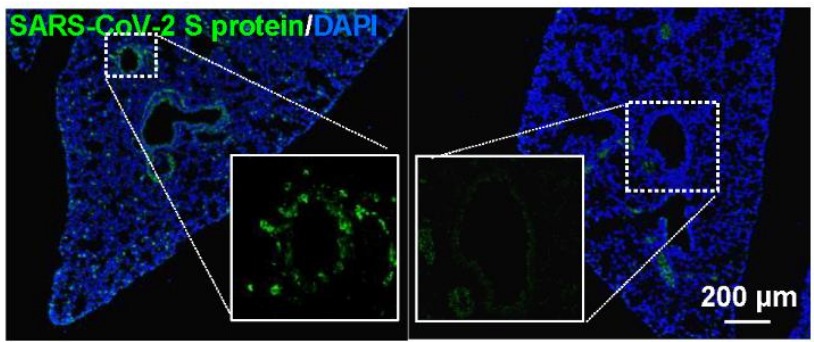

$E$

PBS
RBD-Fc

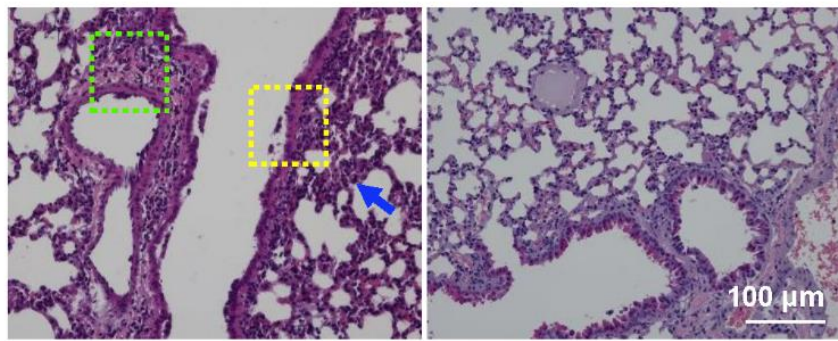

Fig. 4. Protection efficacy of the recombinant RBD-Fc vaccine candidate against MASCp6 challenge in mice. (A) SARS-CoV-2-specific IgG antibody titers were detected by ELISA at two weeks post primary and boost immunization, respectively $(n=10)$. Statistical significance was analyzed by one-way ANOVA. (B) Neutralizing antibody titers against SARS-CoV-2 were determined by the micro-neutralization assay at 2 weeks post boost immunization $(n=10)$. (C) Viral RNA loads in lung of vaccinated mice were detected at 5 days post MASCp6 challenge $(n=5)$. Statistical significance was analyzed by Student's $t$ test. (D) Immunofluorescence staining of mouse lung sections for S protein (green) and DAPI (blue). The dotted boxes are magnified in the panels at the bottom of the same image. (E) H\&E staining of mouse lung sections. Focal perivascular (green square) and peribronchiolar (yellow square) inflammation and thickened alveolar septa (blue arrow) are indicated. n.s., not significant, ${ }^{*} P<0.01,{ }^{* *} P<0.001,{ }^{*}{ }^{*} P<0.0001$. 